\title{
XVIII. The normal and the selective photoelectric effect
}

\section{R. Pohl Ph.D. \& P. Pringsheim Ph.D.}

To cite this article: R. Pohl Ph.D. \& P. Pringsheim Ph.D. (1911) XVIII. The normal and the selective photoelectric effect, Philosophical Magazine Series 6, 21:121, 155-161, DOI: $10.1080 / 14786440108637015$

To link to this article: http://dx.doi.org/10.1080/14786440108637015

册 Published online: 21 Apr 2009.

Submit your article to this journal $\sqsubset \pi$

Џ Article views: 7

Q View related articles $\square$ 
XVIII. The Normal and the Selective Photoelectric Effect. $B y$ R. Pohl, Ph.D., and P. Prixgsheim, J'h.D.*

THE researches made by different authors on the photo1 electric effect lead to some results which seem to be in striking contradiction to each other.

1. E. Ladenburg $\dagger$ and Mohlin $\ddagger$ have shown that the number of electrons produced by the unit of ultraviolet light increases with decreasing wave-lengths.

2. Elster and Geitel § found qualitatively that, for the alkali metals, this number has a maximum in the visible part of the spectrum, and T. Braun $\|$ proved this to be right quantitatively for $\mathrm{Rb}$ and $\mathrm{K}$.

3. On the contrary, Hallwachs 9 denied the existence of these maxima, and from new measurements he concluded that Ladenburg's and Mohlin's law is true also for the alkali metals.

Contradictions of a similar kind are found in the researches on the effects of polarized light.

4. According to Pohl** the orientation of the vectors of ultraviolet light has an influence upon the number of liberated electrons only so far as the absorption of light depends upon it; this is true for solid surfaces of $\mathrm{Cu}$ and $\mathrm{Pt} \uparrow \dagger$, as well as for liquid $\mathrm{Hg} \ddagger \ddagger$.

5. But Elster and Geitel $\S \S$ had found previously for the visible part of the spectrum, that with alkali metals the photoelectric current is proportional to the absorbed energy of light at different angles of incidence only if the electric vector swings at right angles to the plane of incidence: if the electric vector swings in this plane there is only an approximate proportionality between the component of the electric vector normal to the surface, and the photoelectric current due to this component. In this second case the

* Communicated by the Authors.

† E. Ladenburg, Verh. d. D. Phys. Ges. ix. p. 504 (1907).

$\ddagger$ H. Mohlin, Akad. Abhandl., Upsala, 1907.

$\S$ T. Elster and H. Geitel, Wied. Ann. lii. p. 493 (1894).

II T. Braun, Dissertation, Bonn, 1905.

If W. Hallwachs, Verh. d. D. Phys. Ges. xi. p. 514 (1909).

** R. Poǹl, ibid. xi. p. 339 (1909).

+t R. Pohl, ibid. xi. p. 339 (1909).

tł R. Pohl, ibid. xi. p. 609 (1909).

$\$ \S$ T. Elster and H. Geitel, Wied. Ann. lxi. p. 445 (1897). 
factor of proportionality was much larger; hence the ratio of the photo-effect in the two main planes of polarization was found to be sometimes as high as 1:50. This has been confirmed by different authors.

6. Finally, Pohl* found that these observations of Elster and Geitel are true only in the visible part of the spectrum, while in the ultraviolet the alkali metals hehave like the others, the orientation of the electric vector being immaterial.

Now we are going to show how the coexistence of these different facts, though they seem to be absolutely incompatible, may be easily explained by assuming that there is, apart from the normal photoelectric effect, the only one known as yet, still a new selective one. The full report on this subject has been published in the Verhandlungen der Deutschen Physikalischen Gesellschaft, vol. xii. $\dagger$, and all details may be found there; the numbers in [] correspond with the divisions of these papers.

We used a spectroscope with quartz-fluorite lenses, illuminated by a mercury arc-lamp ; the energy of the single lines was measured by means of a Rubeus thermocouple, and the light was thrown through a quartz polarizer and a window of fused quartz into a tube of the type described by Elster and Geitel, which contained the alkali metal or some alloy. By the aid of this apparatus the photoelectric current could be measured, which was produced by the same energy of incident light in the two main planes of polarization and in different parts of the spectrum.

Table I. and fig. 1 show the results for an alloy of mercury and potassinm, containing 2.5 atomic percentages of the alkali [11]. These numbers and the corresponding ones for $\mathrm{Na}$ prove that at an incidence of $60^{\circ}$ the emission of electrons increases continuously with decreasing wave-length, quite independently of the plane of polarization. The effect is larger if the electric vector swings parallel to the plane of incidence ( $E$ il) than for $E \perp$, in consequence of the greater absorption of light which follows from the optical constants [12]. But for the same energy of absorbed light the plane of polarization has no influence upon the intensity of the emission. Hence for this photoelectric effect of the alloys,

* R. Pohl, Verh. d. D. Phys. Ges. xi. p. 715 (1909).

$\dagger$ R. Pohl and P. Pringsheim, Verh. d. D. Phys. Ges. xii. (1910) pp. 215-230, §\$1-9; pp. 249-260, §§10-17; pp. 682-696, §\$18-27; pp. $697-710$, \$ $\$ 28-37$. 
Normal and Selective Photoelectric Effect.

Table I.

2.5 atom. per cent. $R ; 97 \cdot 5$ atom. per cent. $\mathrm{Hg} . \phi=60^{\circ}$.

\begin{tabular}{|c|c|c|c|}
\hline \multirow{2}{*}{ No. } & \multirow[b]{2}{*}{$\begin{array}{c}\text { Wave-length } \\
\mu \mu .\end{array}$} & \multicolumn{2}{|c|}{ Photoelectric current. } \\
\hline & & $\begin{array}{c}\mathrm{E} \| \\
10^{-13} \text { amp. }\end{array}$ & $\underset{10^{-13}}{\mathrm{E}} \stackrel{\mathrm{amp}}{\perp}$ \\
\hline 95 & 436 & 0.45 & $0 \cdot 13$ \\
\hline 90 & 405 & $5 \cdot 0$ & $1 \cdot 4$ \\
\hline $92 \ldots$ & 313 & $52 \cdot 5$ & $18 \cdot 3$ \\
\hline $93 \ldots$ & 254 & $84 \cdot 4$ & 32 \\
\hline
\end{tabular}

Fig. 1. $-\mathrm{K}-\mathrm{Hg}$ alloy ; $\phi=60^{\circ}$.

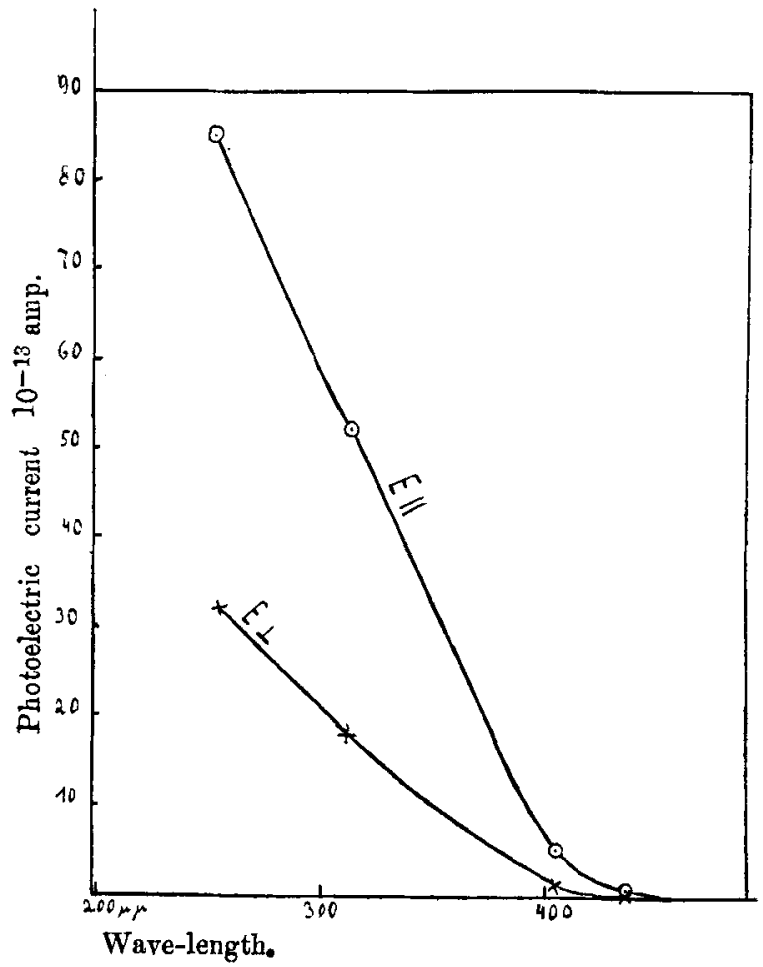


which is due exclusively to the alkalies, the assertions 1 and 4 are true, even in the visible part of the spectrum. We call it the normal effect. All the well-known facts such as the independence of the temperature, the curves of the initial velocity and others refer to this effect, and so it may be explained by the atomistic theory of light according to Planck-Einstein * [18].

The results are very different for pure alkali metals or $\mathrm{Hg}$ alloys of certain concentrations. Also in this case the normal effect exists for $\mathrm{E} \|$ and $\mathrm{E} \perp$ as in fig. 1, but for E $\|$ there is a second effect superposed on the normal one,

Fig. 2.

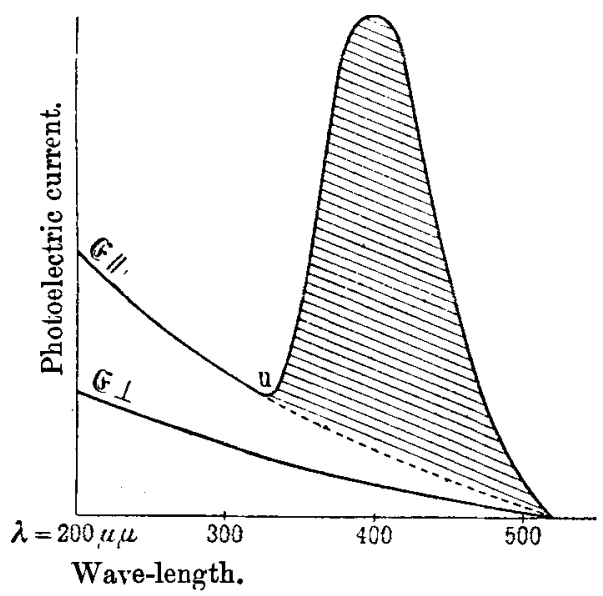

in a short range of the spectrum ; it grows rapidly from a small value to a very great intensity, and decreases then again with decreasing wave-length to zero, suggesting a resonance phenomenon; it is the more intense the stronger the component of the electric vector normal to the surface of the metal. The orientation of plane of polarization is of great importance for this effect, which may be called the selective one. Fig. 2 shows the superposition of the two effects [18]. Fig. 3 and Table IT. contain the results which we obtained with polarized light on a sodium-potassium

* Cf. R. Ladenburg, Jahrb. d. Rad. u. El. vi. pp. 425-487 (1909). 
Normal and Selective Photoelectric Effect.

alloy $(69 \cdot 4$ per cent. K) [10]. In fig. 3 the ultraviolet end of the selective effect cannot yet be recognized; but

Fig. 3.-K-Na alloy; polarized light.

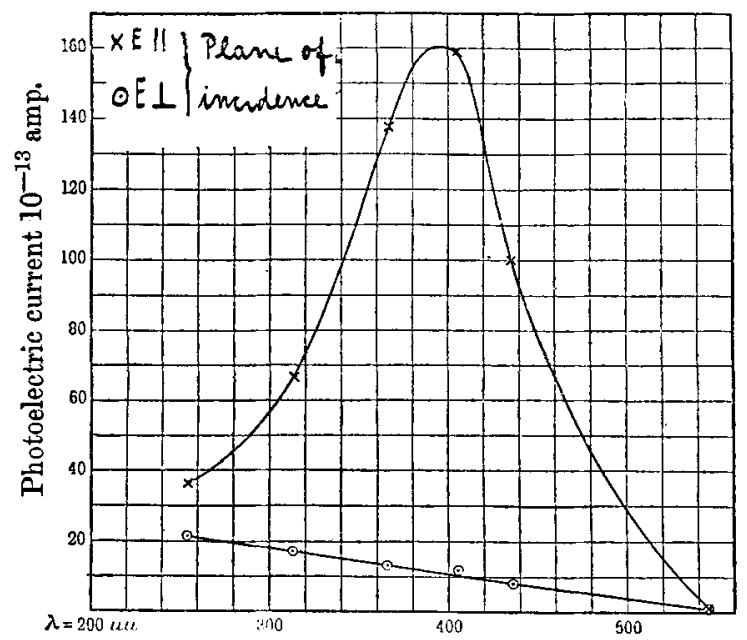

Wave-length.

Fig. 4.-Potassium ; unpolarized light,

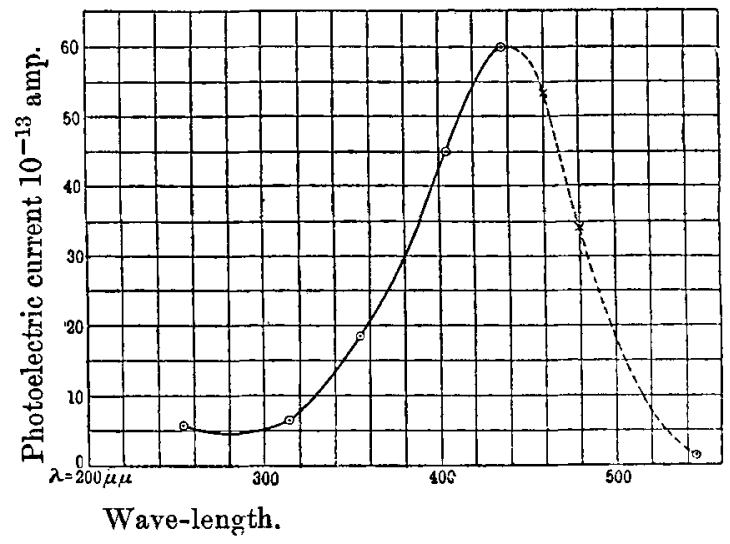

this is easily seen in figs. 4 and 5 , which were observed on $K$ [14] and $R b$ [15] in unpolarized light, and show again 
the addition of the two effects; Tables III. and IV. correspond to these figures.

Fig. 5.-Rubidium; unpolarized light.

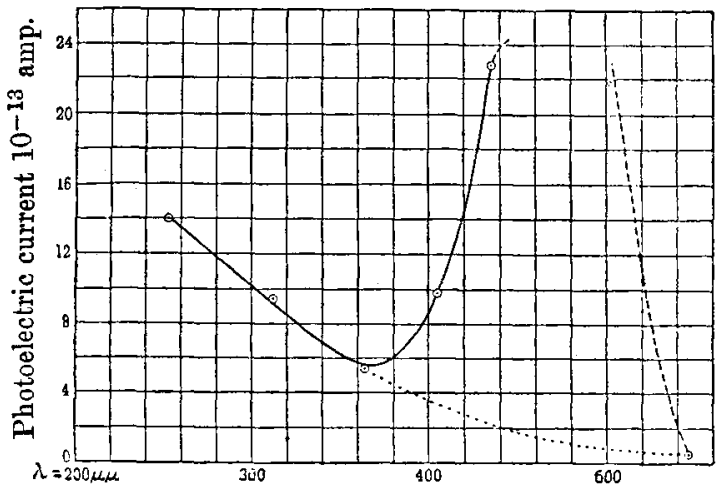

Wave-length.

TABLE II.

$\mathrm{K}-\mathrm{Na}$ alloy. $\phi=60^{\circ}$.
Table III.

Solid K. $\phi=60^{\circ}$.
TABLE IV. Solid Rb. $\phi=60^{\circ}$.

\begin{tabular}{|c|c|c|c|c|c|c|c|c|c|}
\hline \multirow[b]{2}{*}{ No. } & \multirow{2}{*}{$\begin{array}{c}\text { Wave- } \\
\text { length } \\
\mu \mu .\end{array}$} & \multicolumn{2}{|c|}{ Photoelectric current. } & \multirow[b]{2}{*}{ No. } & \multirow[b]{2}{*}{$\begin{array}{c}\text { Wave- } \\
\text { length } \\
\mu \mu .\end{array}$} & \multirow{2}{*}{$\begin{array}{c}\text { Photoelectric } \\
\text { current } \\
10^{-13} \mathrm{amp} .\end{array}$} & \multirow[b]{2}{*}{ No. } & \multirow[b]{2}{*}{$\begin{array}{c}\text { Wave- } \\
\text { length } \\
\mu \mu .\end{array}$} & \multirow[b]{2}{*}{$\begin{array}{c}\text { Photoelectric } \\
\text { current } \\
10^{-13} \text { amp. }\end{array}$} \\
\hline & & $\mid \begin{array}{c}\mathbf{E} \\
10^{-13} \mathrm{amp}\end{array}$ & $\frac{E \perp}{10^{-13} \text { amp. }}$ & & & & & & \\
\hline $1 \ldots$ & 546 & $1 \cdot 0$ & $0 \cdot 11$ & 122 & 546 & $0 \cdot 0$ & 135 & 546 & 0.47 \\
\hline $2 \ldots$ & 436 & $100 \cdot 0$ & $8 \cdot 0$ & 123 & 436 & 60 & 134 & 436 & $22 \cdot 9$ \\
\hline $3 .$. & 406 & $159 \cdot 0$ & $12 \cdot 3$ & 124 & 406 & 45 & 133 & 406 & $9 \cdot 8$ \\
\hline $4 \ldots$ & 365 & 138 & $13 \cdot 0$ & 125 & 365 & $18 \cdot 4$ & 132 & 365 & $5 \cdot 4$ \\
\hline $5 \ldots$ & 313 & $66 \cdot 7$ & $17 \cdot 1$ & 126 & 313 & 6.3 & 131 & 313 & $9 \cdot 4$ \\
\hline $6 \ldots$ & 254 & $36 \cdot 2$ & $21 \cdot 0$ & 127 & 254 & $5 \cdot 8$ & 129 & 254 & $12 \cdot 6$ \\
\hline
\end{tabular}

There is no more difficulty in explaining the assertions $2,3,5$, and 6 with the aid of the figs. $2-5$.

(2) Elster and Geitel and Braun, using visible light at an oblique incidence, obtained the addition of the two effects, and as the selective one is much stronger their curves had a maximum in the visible part of the spectrum.

(3) In Hallwachs's experiments the light being incident 
normally had no electric vector swinging in this direction, and so the author measured only the normal effect which increases continuously with decreasing wave-length.

(5) Elster and Geitel investigated the influence of polarization only in that part of the spectrum in which the $\mathrm{K}-\mathrm{Na}$ alloy has its selective effect. Consequently they found only for $E \perp$, that at different angles of incidence the emission of electrons was proportional to the absorbed energy; and the ratio of the effects in the two main planes of polarization had naturally values, which like 1:50* are much too large to be only explained by the difference in the absorution of light, and which prove the existence of some special efficacy of $\mathrm{E} \|[19]$.

(6) The same was true in Pohl's experiments, in which above the ultraviolet end $u$ of the selective effect (fig. 2) the singularity of $\mathbf{E} \|$ disappears, so that only the normal effect is left.

Inasmuch as all the contradictions which we spoke of in the beginning are explained now, we think that we are justified in saying that a new selective effect exists, apart from the normal one. We do not as yet know much about the true nature of this effect, but from experiments made on $\mathrm{K}-\mathrm{Hg}$ alloys [37] and on the influence of the angle of incidence $[27]$, we conclude that it is a molecular resonance phenomenon, in which the electrons follow directly the electric vector; at any rate it cannot be explained by the "Quantentheorie" of Planck-Einstein.

We are continuing the researches with the aid of a grant from the Jagor Fund (Berlin), for which we wish to express our best thanks.

Physikalisches Institut der Universität Berlin, October 1910.

XIX. On the Maintenance of Periodic Motion by Solid Friction. By Andrew Stephenson $\dagger$.

1. TWE maintenance of periodic motion by solid friction 1 demonstrates that such friction diminishes as the velocity increases through a small range at least. However the friction may vary there is always a position of equilibrium and the small motion about it is evidently of type

$$
\ddot{x}+(\kappa-\lambda) \dot{x}+n^{2} x=0,
$$

* We got even the ratio $1: 300$ in $\mathrm{K}-\mathrm{Na}$ alloys, in which the normal effect was comparatively much smaller than in fig. 3 .

$\uparrow$ Communicated by the Author.

Phil. Mag. S. 6. Vol. 21. No. 121. Jan. 1911. 